\title{
A Study of Epidemiology of Hypertension in an Urban Slum Community of Mumbai
}

Prasad Tukaram Dhikale ${ }^{1^{\star}}$, Mridula J Solanki ${ }^{2}$ and Saurabh Ram Bihari Lal Shrivastava ${ }^{3}$

${ }^{1}$ Department of Community Medicine, Sri Manakula Vinayagar Medical College and Hospital, Pondicherry, India

${ }^{2}$ Department of Community Medicine, Seth Gordhandas Sunderdas Medical College and King Edward Memorial Hospital, Mumbai, India

${ }^{3}$ Department of Community Medicine, Shri Sathya Sai Medical College and Research Institute, Kancheepuram, India

\begin{abstract}
Background: Hypertension is often asymptomatic disease and can lead to lethal complications. So the present study was done with the objective of studying the prevalence and determinants of hypertension and to assess the applicability of the rule of halves in hypertension in the urban slum community.

Methods: It was a community based cross-sectional study conducted from April 2010 to March 2012, among people above 18 years of age residing in an urban slum of Mumbai, from Malwani slum. Multistage sampling procedure was employed and total sample size was 1089. Statistical analysis was done by using SPSS 16 software. Frequency distribution was calculated for all the socio-demographic variables and chi-square test was also employed to study the association between risk factors and presence of hypertension.

Results: The prevalence of hypertension in the study group was $23.59 \%$. The prevalence of hypertension in males and females was $23.15 \%$ and $24.04 \%$, respectively (using blood pressure $\geq 140 / 90$ as Hypertension). Prevalence of hypertension showed a significant positive association with age, family history of hypertension, body mass index, absence of physical activity, smokeless tobacco, tobacco smoking, alcohol, mixed diet. The hypertensives aware of suffering from hypertension were $41.6 \%$. Out of the hypertensives who were aware of suffering from hypertension $55.5 \%$ were taking treatment. While only $47.4 \%$ of hypertensives who were taking treatment had controlled blood pressure.

Conclusion: The prevalence of hypertension in the current study was $23.59 \%$ and thus it still remains a major public health concern in urban slum settings. The rule of halves was still prevalent and the awareness about hypertension and its regular treatment should be given to the community.
\end{abstract}

Keywords: Hypertension; Urban slum; Prevalence; Rule of halves

\section{Introduction}

Hypertension is directly responsible for $57 \%$ of all stroke deaths and $24 \%$ of all coronary heart disease deaths in India [1]. This fact is important because hypertension is a controllable disease and a $2 \mathrm{mmHg}$ population-wide decrease in $\mathrm{BP}$ can prevent 1,51,000 stroke and 1,53,000 coronary heart disease deaths [1]. Often the disease is asymptomatic. Even though, many studies have been performed in urban slums, lot of them lack awareness about the health problems. The present study has been conducted with an objective to estimate the prevalence and determinants of hypertension and to assess the applicability of the rule of halves in the urban slum community.

\section{Material and Methods}

\section{Study setting}

The study area was an urban slum Malwani, Mumbai, which comes under the service area of the Urban Health and Training Centre, Department of Community Medicine, King Edward Memorial Hospital and Seth Gordhandas Sunderdas Medical College, Mumbai. The population of this area was $1,55,830$.

\section{Study design-community based cross-sectional study}

Study participants: People above 18 years from Malwani slum. Pregnant women were excluded. Study duration was from April 2010 to March 2012.

Sample size and sampling: Sample size was calculated by using statistical formula, $\mathrm{n}=4 \mathrm{pq} / 12, \mathrm{p}=27 \%$ from the pilot study done in this area, $\mathrm{q}=100-\mathrm{p}, \mathrm{l}=10 \%$ of $\mathrm{p}, \mathrm{n}=1081$. In this study, multistage sampling procedure was used. In first stage, amongst the 4 colonies, one colony was selected for study by simple random sampling (lottery method). In the second stage, out of 70 plots, 28 plots were selected by random sampling by using numbers allotted to each plot. In third stage from each of the 28 plots, 10 households were selected using systematic sampling. From the 280 households all people above 18 years who consented were included in the study. If a house was locked next house was included.

Data collection tool: A pre-tested semi-structured questionnaire was used for data collection. All the study participants were interviewed face-to face using the questionnaire after obtaining their written informed consent.

${ }^{*}$ Corresponding author: Prasad Tukaram Dhikale, 3rd floor, Department of Community Medicine, Sri Manakula Vinayagar Medical College and Hospital, Kalitheerthalkuppam, Madagadipet, Puducherry - 605107, India, Tel: +917418434404; E-mail: drdpkem@gmail.com

Received April 16, 2015; Accepted May30, 2015; Published June 06, 2015

Citation: Dhikale PT, Solanki MJ, Shrivastava SR (2015) A Study of Epidemiology of Hypertension in an Urban Slum Community of Mumbai. Biol Med S3: 003. doi: 10.4172/0974-8369.S3-003

Copyright: (c) 2015 Dhikale PT, et al. This is an open-access article distributed under the terms of the Creative Commons Attribution License, which permits unrestricted use, distribution, and reproduction in any medium, provided the original author and source are credited. 
Study variables: Information regarding sociodemographic factors, family history of hypertension, physical activity, smoking, alcohol consumption and diet were collected. Anthropometric measurements of height and weight were taken using standardized methods.

Operational definitions: Use of smokeless tobacco was taken as tobacco chewing, eating gutkha, tobacco in pan or/and mishri application in the past 6 months. Tobacco smoking was taken as smoking bidi or/ and cigarette in the past 6 months. Alcohol consumption was taken as consumption of alcohol in the past 6 months.

Physical activity was measured using the International Physical Activity Questionnaire (short version) [2]. Total metabolic equivalents/ week (MET/wk) were calculated and individuals were grouped as physically inactive ( $<495 \mathrm{MET} / \mathrm{wk})$ and physically active ( $\geq 495 \mathrm{MET} / \mathrm{wk})$. Generalized obesity was defined using the new Asia Pacific guidelines for obesity using body mass index values, that is, underweight $(<18.5$ $\left.\mathrm{kg} / \mathrm{m}^{2}\right)$, normal $\left(18.5-22.99 \mathrm{~kg} / \mathrm{m}^{2}\right)$, overweight $\left(23-24.99 \mathrm{~kg} / \mathrm{m}^{2}\right)$ and obese $\left(\geq 25 \mathrm{~kg} / \mathrm{m}^{2}\right)$.

Blood pressure (BP) was measured by using a mercury sphygmomanometer by auscultation method in sitting position. Three readings were taken 10 minutes apart by a single observer and the average of the three readings was considered as the final blood pressure reading. The blood pressure measurements were done as per WHO criteria. The subjects were classified according to the 7th report of joint national committee classification [3]. Those individuals who were known hypertensives (with or without treatment) were also defined as hypertensives (irrespective of their blood pressure readings). Awareness of suffering from hypertension was defined on the basis of participants report of prior diagnosis of hypertension by a health professional. Subjects who were aware about their hypertension and receiving antihypertensive drug therapy at the time of survey were labelled as treated hypertension, and if the recorded measurements of blood pressure in this group were below 140/90 $\mathrm{mmHg}$ they were considered as controlled blood pressure.

\section{Statistical Analysis}

Statistical analysis was done by using SPSS 16 software. Frequency distribution was calculated for all the socio-demographic variables and chi-square test was also employed to study the association between risk factors and presence of hypertension.

\section{Ethical considerations}

Clearance from the Institutional Ethics Committee was obtained. Written informed consent was obtained from the study subjects before obtaining any information from them.

\section{Results}

Out of 1089 study participants, there were 540 males and 549 females. Majority of the subjects 340 (31.1\%) were from the age group 18 to 30 year (Table 1). The religion for majority of the subjects 891 (81.8\%) was Muslim. Majority of the subjects 550 (50.5\%) belonged to the upper lower socioeconomic classes using Kuppuswamy's socioeconomic status scale modified for 2007. The mean systolic and diastolic blood pressure among the normotensives was $118.7 \mathrm{~mm} \mathrm{Hg}( \pm$ $1.8)$ and $77.6 \mathrm{~mm} \mathrm{Hg}( \pm 1.1)$. On the other hand, among hypertensive subjects, the mean systolic and diastolic blood pressure was $146.4 \mathrm{~mm}$ $\mathrm{Hg}( \pm 2.6)$ and $107.4 \mathrm{~mm} \mathrm{Hg}( \pm 1.5)$.
As seen in Table 2, the prevalence of hypertension in the study group was (257/1089) $23.59 \%$. The prevalence of hypertension in males and females was (125/540) $23.15 \%$ and (132/549) $24.04 \%$ respectively. The factors observed to be significantly associated with hypertension were: age, family history of hypertension, body mass index, physical activity, use of smokeless tobacco, smoking tobacco, alcohol consumption and diet.

Out of the 257 hypertensives only 107 (41.6\%) were aware that they were suffering from hypertension. Out of these 107 who aware that they were suffering from hypertension only 59 (55.1\%) were taking treatment. Out of these 59 who were taking treatment only $28(47.4 \%)$ had controlled blood pressure.

\section{Discussion}

The prevalence of hypertension in the study participants was $23.59 \%$. The prevalence of hypertension in males and females was $23.15 \%$ and $24.04 \%$ respectively. This prevalence was similar to the ICMR study in 1994 involving 3050 urban residents, which demonstrated 25\% and $29 \%$ prevalence of hypertension (Criteria: $\geq 140 / 90 \mathrm{~mm}$ of $\mathrm{Hg}$ ) among males and females respectively in urban Delhi [4]. Findings of an epidemiological study revealed that prevalence of hypertension was $26.7 \%$ and $27.6 \%$ among males and females respectively. It was higher as compared to our study as the age group of participants were above 30 years $[5,6]$. In a large community-based study done in Mumbai, the prevalence of hypertension was $44 \%$ among men and $45 \%$ among women [7]. A study done in Southern part of India reported the prevalence of hypertension to be $9 \%$ [8]. A study done among executives in Mumbai found the prevalence of hypertension as $27 \%$ and $28 \%$ among men and women respectively [9].

In our study prevalence of hypertension showed a significant positive association with age, family history of hypertension, body mass index, absence of physical activity, smokeless tobacco, tobacco smoking, alcohol and mixed diet. In a similar study done in Chhattisgarh prevalence of hypertension showed a significant positive association with body mass index, physical activity and age, but inverse association was observed with alcohol and smoking [10]. A study done in Tirupati also reported a higher proportion of hypertension with BMI $>25 \mathrm{~kg} / \mathrm{m}^{2}$, family history of hypertension, smoking and lack of physical exercise [8].

The rule of halves was still prevalent in our study area similar finding was there in the Chennai Urban Population Study (CUPS) where $37.3 \%$ hypertensives were aware of their hypertension. Of the known hypertensives, 50\% were under any kind of antihypertensive therapy. Of these, only $40 \%$ had blood pressure under control [11]. According to P Marques-Vidal Rule of halves might be valid for developing countries [12]. In a study done at Tirupati $83.7 \%$ of hypertensives were aware of their hypertension; all of those aware were under-treatment; among the

\begin{tabular}{|c|c|c|c|}
\hline $\begin{array}{c}\text { Age groups } \\
\text { (years) }\end{array}$ & Males (\%) $\mathbf{n}=\mathbf{5 4 0}$ & $\begin{array}{c}\text { Females (\%) } \mathbf{n} \\
\mathbf{= 5 4 9}\end{array}$ & Total (\%) $\mathbf{n}=\mathbf{1 0 8 9}$ \\
\hline $18-30$ & $168(31.1)$ & $172(31.3)$ & $340(31.2)$ \\
\hline $31-40$ & $123(22.7)$ & $132(24)$ & $255(23.4)$ \\
\hline $41-50$ & $101(18.7)$ & $105(19.1)$ & $206(18.9)$ \\
\hline $51-60$ & $79(14.6)$ & $76(13.8)$ & $155(14.2)$ \\
\hline $61-70$ & $46(8.5)$ & $43(7.8)$ & $89(8.1)$ \\
\hline$>71$ & $23(4.2)$ & $21(3.8)$ & $44(4)$ \\
\hline \multicolumn{4}{|c|}{ Table 1: Age-sex distribution of the study subjects. } \\
\hline
\end{tabular}


Citation: Dhikale PT, Solanki MJ, Shrivastava SR (2015) A Study of Epidemiology of Hypertension in an Urban Slum Community of Mumbai. Biol Med S3: 003. doi: 10.4172/0974-8369.S3-003

Page 3 of 3

\begin{tabular}{|c|c|c|c|c|c|}
\hline \multirow{2}{*}{\multicolumn{2}{|c|}{ Determinants of hypertension }} & Hypertensives (\%) & \multirow{3}{*}{$\begin{array}{c}\text { Nonhypertensives (\%) } \mathbf{n}=\mathbf{8 3 2} \\
415(76.8)\end{array}$} & Total (\%) & \multirow{2}{*}{$p$ value } \\
\hline & & $n=257$ & & $n=1089$ & \\
\hline \multirow{2}{*}{ Sex } & Males & $125(23.2)$ & & $540(49.6)$ & \multirow{2}{*}{$>0.05$} \\
\hline & Females & $132(24.1)$ & $417(75.9)$ & $549(50.4)$ & \\
\hline \multirow{6}{*}{ Age group (years) } & $18-30$ & $1(0.4)$ & $339(40.7)$ & $340(31.2)$ & \multirow{6}{*}{$<0.05$} \\
\hline & $31-40$ & $32(12.4)$ & $223(26.8)$ & $255(23.4)$ & \\
\hline & $41-50$ & $62(24.1)$ & $144(17.3)$ & $206(18.9)$ & \\
\hline & $51-60$ & $83(32.3)$ & $72(8.6)$ & $155(14.2)$ & \\
\hline & $61-70$ & $54(21)$ & $35(4.2)$ & $89(8.1)$ & \\
\hline & $71+$ & $25(9.7)$ & $19(2.2)$ & $44(4)$ & \\
\hline \multirow{2}{*}{$\begin{array}{l}\text { Family history of } \\
\text { hypertension }\end{array}$} & Yes & $113(44.1)$ & $102(12.3)$ & $215(19.7)$ & \multirow{2}{*}{$<0.05$} \\
\hline & No & $144(56)$ & $730(87.7)$ & $874(80.2)$ & \\
\hline \multirow{4}{*}{$\begin{array}{c}\text { Classification according } \\
\text { to BMI }\end{array}$} & Under weight & $6(2.3)$ & $180(21.6)$ & $186(17)$ & \multirow{4}{*}{$<0.05$} \\
\hline & Normal & $69(26.8)$ & $443(53.2)$ & $512(47)$ & \\
\hline & Over weight & $63(24.5)$ & $52(6.2)$ & $115(10.6)$ & \\
\hline & Obese & $119(46.3)$ & $157(18.9)$ & $276(25.3)$ & \\
\hline \multirow{2}{*}{ Physical activity } & Active & $67(26)$ & $325(39)$ & $392(36)$ & \multirow{2}{*}{$<0.05$} \\
\hline & Inactive & $190(74)$ & $507(61)$ & $697(64)$ & \\
\hline \multirow{2}{*}{ Smokeless tobacco } & Yes & $60(23.3)$ & $129(15.5)$ & $189(17.3)$ & \multirow{2}{*}{$<0.05$} \\
\hline & No & $197(76.6)$ & $703(84)$ & $900(82.6)$ & \\
\hline \multirow{2}{*}{ Tobacco smoking } & Yes & $38(14.7)$ & $67(8)$ & $105(9.6)$ & \multirow{2}{*}{$<0.05$} \\
\hline & No & $219(85.2)$ & $765(92)$ & $984(90.3)$ & \\
\hline \multirow{2}{*}{ Alcohol } & Yes & $49(19)$ & $82(9.8)$ & $131(12)$ & \multirow{2}{*}{$<0.05$} \\
\hline & No & $208(81)$ & $750(90.2)$ & 958 (87.9) & \\
\hline \multirow{2}{*}{ Diet } & Vegetarian & $14(5.4)$ & $93(11.2)$ & $76(6.9)$ & \multirow{2}{*}{$<0.05$} \\
\hline & Mixed & $243(94.5)$ & 739 (88.7) & $1013(93)$ & \\
\hline
\end{tabular}

Table 2: Hypertension and its determinants.

treated, $41.7 \%$ had satisfactory control of their hypertension [8]

The major strengths of this study were it was a community based study with adequate sample size. Limitation of the study was that hip and waist circumference was not taken as there was no female to accompany the first author for taking measurements in females. The age adjustment was not done. The study was performed in a small geographic area.

\section{Conclusion}

The prevalence of hypertension in the current study was $23.59 \%$ and thus it still remains a major public health concern in urban slum settings. Health education should be given to the community about hypertension, its risk factors, early diagnosis and regular treatment of hypertension.

\section{References}

1. Rodgers A, Lawes C, MacMahon S (2000) Reducing the global burden of blood pressure-related cardiovascular disease. J Hypertens Suppl 18: S3-6.

2. Sanges D, Culla G, Jesi AP, Mari F (2013) (Italian survey on physical activity of the members of GICR-iACPR 2012). Monaldi Arch Chest Dis 80: 90-95.

3. U.S. Department of Health and Human Services (2004) The seventh report of the joint national committee onprevention, detection, evaluation, and treatment of high blood pressure. National Institutes of Health, USA.

4. Ministry of Health and Family Welfare, Government of India, World Health Organization (2004) National Cardiovascular Disease Database - Sticker No: SE/04/233208.

5. Sidhu S, Kaur J, Randhawa R (2014) Prevalence of Hypertension in India: A Review. Asian J Multidisc Stu 2:141-155.

6. Anand MP (2000) Prevalence of hypertension amongst Mumbai executives. $J$ Assoc Physicians India 48: 1200-1201.

7. Gupta PC, Gupta R (1999) Hypertension prevalence and blood pressure trends among 99,589 subjects in Mumbai, India. Indian Heart J 51:691.

8. Reddy SS, Prabhu GR (2005) Prevalence and Risk Factors of Hypertension in Adults in an Urban Slum, Tirupati, A.P. Ind J Com Med 30:84-86.

9. Anand MP (2000) Prevalence of hypertension amongst Mumbai executives. J Assoc Physicians India 48: 1200-1201.

10. Alam MN, Soni GP, Jain KK, Verma S, Panda PS (2015) Prevalence and determinants of hypertension in elderly population of Raipur city, Chhattisgarh. Int J Res Med Sci 3:568-573.

11. Deepa R, Shanthirani CS, Pradeepa R, Mohan V (2003) Is the 'rule of halves' in hypertension still valid?--Evidence from the Chennai Urban Population Study. J Assoc Physicians India 51: 153-157.

12. Marques-Vidal P, Tuomilehto J (1997) Hypertension awareness, treatment and control in the community: is the 'rule of halves' still valid? J Hum Hypertens 11 : 213-220. 